\title{
The effects of Curcuma longa and curcumin on reproductive systems
}

\author{
${ }^{1}$ Mohebbati R, ${ }^{2}$ Anaeigoudari A, ${ }^{3}$ Khazdair MR \\ ${ }^{1}$ Department of Physiology, School of Medicine, Mashhad University of Medical Sciences, Mashhad, Iran; \\ ${ }^{2}$ Department of Physiology, School of Medicine, Jiroft University of Medical Sciences, Jiroft, Iran; ${ }^{3}$ Student Research \\ Committee, Neurogenic Inflammation Research Center, Mashhad University of Medical Sciences, Mashhad, Iran \\ E-mail: Khazdeirmr921@mums.ac.ir
}

Objective. Curcuma longa (C. longa) was used in some countries such as China and India for various medicinal purposes. Curcumin, the active component of $C$. longa, is commonly used as a coloring agent in foods, drugs, and cosmetics. C. longa and curcumin have been known to act as antioxidant, anti-inflammatory, anti-mutagen, and anti-carcinogenic agents. The attempt of the present review was to give an effort on a detailed literature survey concentrated on the protective effects of $C$. longa and curcumin on the reproductive organs activity.

Methods. The databases such as, PubMed, Web of Science, Google Scholar, Scopus, and IranMedex, were considered. The search terms were "testis" or "ovary" and "Curcuma longa", "curcumin", "antioxidant effect", "anti-inflammatory effect" and "anti-cancer effect".

Results. C. longa and curcumin inhibited the production of the tumor necrosis factor- $\alpha$ (TNF- $\alpha$ ) and prostaglandin E2 (PGE2) and increased the caspases (3, 8 and 9) activities in HL-60 prostate cancer. Furthermore, C. longa and curcumin suppressed the vascular endothelial growth factor (VEGF), phosphorylated signal transducers and activators of the transcription 3 (STAT) and matrix metalloproteinase-9 (MMP-9) in ovarian cancer cell line.

Conclusion. C. longa and curcumin might decrease the risk of cancer and other malignant diseases in the reproductive system. C. longa and curcumin have a protective effect on the reproductive organs activity such as, anti-inflammatory, anti-apoptotic, and antioxidant effects in normal cells but showed pro-apoptotic effects in the malignant cells. Therefore, different effects of $C$. longa and curcumin are dependent on the doses and the type of cells used in various models studied.

Key words: Curcuma longa, curcumin, therapeutic effects, reproductive system

Medical plants have been considered as a major source of therapeutic agents in the traditional medicine to cure human diseases. The use of the medicinal plants and traditional medicine was interested and started mainly in the last decade because it was a belief that the natural drugs are healthier than the synthetic ones (Cragg and Newman 2005). Turmeric is a spice derived from the Curcuma longa (C. longa) rhizomes (Eigner and Scholz 1999). The yellow color of turmeric comes from the polyphenolic pigments known as curcuminoids (Araujo and Leon 2001). Turmeric has been used in India for different medicinal purposes since centuries (Akram et al. 2010). It has been reported that C. longa extract has renal protective (Aggarwal and Harikumar 2009; Mohebbati et al. 2016), hepatoprotective (Deshpande et al. 1998; Naik et al. 2004; Khazdair et al. 2016), cardioprotective (Mohanty et al. 2004; Aggarwal and Harikumar 2009; Srivastava and Mehta 2009), anti-diabetic (Kowluru and Kanwar 2007), neuroprotective (Shukla et al. 2003; Aggarwal and Harikumar 2009), and gonadoprotective effects (Ilbey et al. 2009; Azza et al. 2011).

Corresponding author: M.R. Khazdair, Student Research Committee, Neurogenic Inflammation Research Centre, Mashhad University of Medical Sciences, Mashhad, Iran, post code 9177948564; phone: 0098513 8002216; fax: 0098513 8828564; e-mail: Khazdeirmr921@mums.ac.ir; e-mail:m.khazdair@yahoo.com. 
Curcumin is the major and active biological compound of $C$. longa. The major therapeutic effects of $C$. longa was attributed to the curcumin (Sharma et al. 2005). The pharmacological safety of curcumin has been revealed (Ammon and Wahl 1991) and its safety for human consumption has been approved by the U.S. Food and Drug Administration (FDA) (Chainani-Wu 2003).

The pharmacological effects of curcumin, including anti-inflammatory (Jurenka 2009), antioxidant, and anticancer ones (Kuttan et al. 1985; Swany et al. 2008; Aggarwal and Harikumar 2009; Wilken et al. 2011), have been reported. The anti-carcinogenic effects of curcumin due to free-radical scavenging, as well as their ability to increase glutathione levels, and relieving in hepatic detoxification of mutagens and carcinogens, have been shown (Kunchandy and Rao 1990; Akram et al. 2010).

The results of the studies have shown that curcumin exerts advantageous effects on the sexual glands, testis, and ovary, which may be due to antioxidant (Sahoo et al. 2008), anti-inflammatory (Farombi et al. 2007), anti-cancer (Cort et al. 2012), and anti-apoptotic properties (Aktas et al. 2012). Therefore, in this article we reviewed the effects of $C$. longa and curcumin on sexual glands, testis and ovary, in the in vitro and in vivo conditions.

The data of this review article have been obtained by searching in PubMed, Web of Science, Google Scholar, Scopus, and IranMedex until the end of March 2017. The search terms were "testis" or "ovary" and "Curcuma longa", "curcumin”, "antioxidant effect", "anti-inflammatory effect" and "anti-cancer effect".

\section{The effect of C. Longa and curcumin on male reproductive system}

In vitro (cellular) studies. The anti-inflammatory activity of $C$. longa extracts on LPS-induced production of tumor necrosis factor alpha (TNF- $\alpha$ ) and prostaglandin E2 $\left(\mathrm{PGE}_{2}\right)$ in HL-60 cells showed that C. longa inhibited production of TNF- $\alpha$ and $\mathrm{PGE}_{2}$ in HL-60 cells (Lantz et al. 2005).

The pro-apoptotic effect of the curcumin on the human neutrophil apoptosis has been evaluated. Curcumin $(10-50 \mu \mathrm{M})$ increased the constitutive neutrophil apoptosis and decreased the migration and myeloperoxidase releases. Curcumin applied proapoptotic effect on the human neutrophil is acting via p38 mitogen-activated protein kinase (MAPK) or increasing in caspase-3 activity (Hu et al. 2005).

The apoptotic potential of the curcumin on both the androgen-dependent and the androgen-indepen- dent prostate cancer cells showed that $2 \%$ curcumin in the synthetic diet significantly decreased the extent of cell proliferation and significantly increased the extent of the apoptosis, which was measured by in situ cell death assay. Furthermore, curcumin significantly decreased the micro vessel density in the androgen-dependent LNCaP prostate cancer cells (Dorai et al. 2001). The effects of the curcumin and bleomycin on apoptosis in human malignant testicular germ cells (NCCIT cells) have been investigated. Curcumin $(5 \mu \mathrm{M}), \mathrm{H}_{2} \mathrm{O}_{2}(35 \mu \mathrm{M})$ and bleomycin $(120 \mu \mathrm{g} / \mathrm{ml})$ increased the apoptotic markers, including caspases (3, 8 and 9) activities, Bax and cytoplasmic Cyt-C levels but decreased the Bcl-2 level (Cort et al. 2013).

It has been reported that curcumin $(5,10$ and $15 \mu \mathrm{M})$ inhibited the viability of NTera-2 human malignant testicular germ cells (Zhou et al. 2013). Curcumin has been revealed to inhibit the colony formation in both NTera-2 and F9 mouse teratocarcinoma stem cells. It has been proposed that curcumin $(15 \mu \mathrm{M})$ can suppress AP- $2 \gamma$, a marker of testicular germ cell tumors, and inhibit amplification and expression of NTera-2 cells (Zhou et al. 2013).

In vivo (animal) studies. Administration of $C$. longa extract ( $1 \mathrm{mg} / \mathrm{kg}$, p.o.) reduced the serum levels of cholesterol, triglycerides, and phospholipids as well as the fertility in the male rats (Purohit 1999). Aqueous rhizome extract of C. longa (600 mg/kg b.w. per day for 56 and 84 days) orally administered to male mice of the Parkes (P) strain significantly reduced the weights of the testis, epididymis, and seminal vesicle compared to controls. Moreover, the number of spermatozoa in cauda epididymidis, motility, and viability were significantly reduced, whereas the number of morphologically abnormal spermatozoa in the extract-treated group significantly increased compared to the control group (Mishra and Singh 2009). C. longa extract also reduced the diameter of the seminiferous tubules, the height of the germinal epithelium, the levels of sialic acid in the epididymis, fructose in the seminal vesicle, and serum level of testosterone, while ; the muscle layer surrounding the glandular epithelium increased compared to the control group (Mishra and Singh 2009).

The aqueous and alcoholic extracts of C. longa ( $500 \mathrm{mg} / \mathrm{kg}$ for 60 days) decreased the seminal vesicle and ventral prostate, and the weight of testes and epididymides in male albino rats. It has been shown that the aqueous and alcoholic extract of $C$. longa decreased the sperm motility in cauda epididymides, and sperm density in the testes and cauda epididymi- 
des. Both of the extracts also reduced the size of the seminiferous tubules of testes, number of spermatogonia, spermatocytes, and spermatids. The seminiferous tubules and Leydig cells nuclei diameters were significantly reduced in the extract-treated groups compared to control. (Ashok and Meenakshi 2004).

The acute and chronic oral toxicity of ethanolic extracts of $\mathrm{C}$. longa in mice were studied. The sperm motility and sperm counts increased in both acute dosages $(0.5,1$ and $3 \mathrm{~g} / \mathrm{kg})$ and the chronic dose of extract (100 mg/kg) (Qureshi et al. 1992).

Effects of $C$. longa and curcumin on adverse reproductive effects induced by water nitrate pollution in male rats have been examined (Azza et al. 2011). The results have shown that in nitrate-exposed rats, the serum levels of testosterone, dehydroepiandrosterone (DHEA), epididymal sperm number, total protein, RNA, and DNA contents in serum and testis significantly decreased, whereas lipid profile, including total lipid, total cholesterol, triglycerides, and phospholipids were significantly increased in serum and testis. Testicular antioxidant components, including superoxide dismutase (SOD), glutathione (GSH), and $\gamma$-glutamyl transpeptidase $(\gamma$-GT), were reduced in testis of nitrate-exposed rats. C. longa $(1 \% \mathrm{w} / \mathrm{w})$ and curcumin $(20 \mathrm{mg} / \mathrm{kg}$, p.o.) have been shown to be effective in reducing the nitrate-induced reproductive alterations, as shown by normalized lipid peroxidation, lipid profile, antioxidant components, total protein, DNA, RNA, and sperm number (Azza et al. 2011).

These results have indicated that the aqueous extract of $C$. longa had adverse effects on the spermatogenesis, motility, morphology, viability, and number of spermatozoa in the cauda epididymidis, and these adverse effects were caused due to the effects on function of the gland and deficiency of testosterone. Furthermore, acute and the chronic doses of C. longa extract increased sperm motility and sperm counts, which may be due to effects of the $C$. longa extract on function of the gland.

The role of the curcumin on pesticide lindane-induced adverse effects on the testis has been studied (Sharma and Singh 2010). Administration of curcumin $(100 \mathrm{mg} / \mathrm{kg})$ to lindane-exposed male Wistar rats (daily $30 \mathrm{mg} / \mathrm{kg}$ ) resulted in decreasing testicular sperm head count, weight of testes and cauda epididymis, and sperm motility, while increased abnormal tail and head sperm morphology. In addition, the

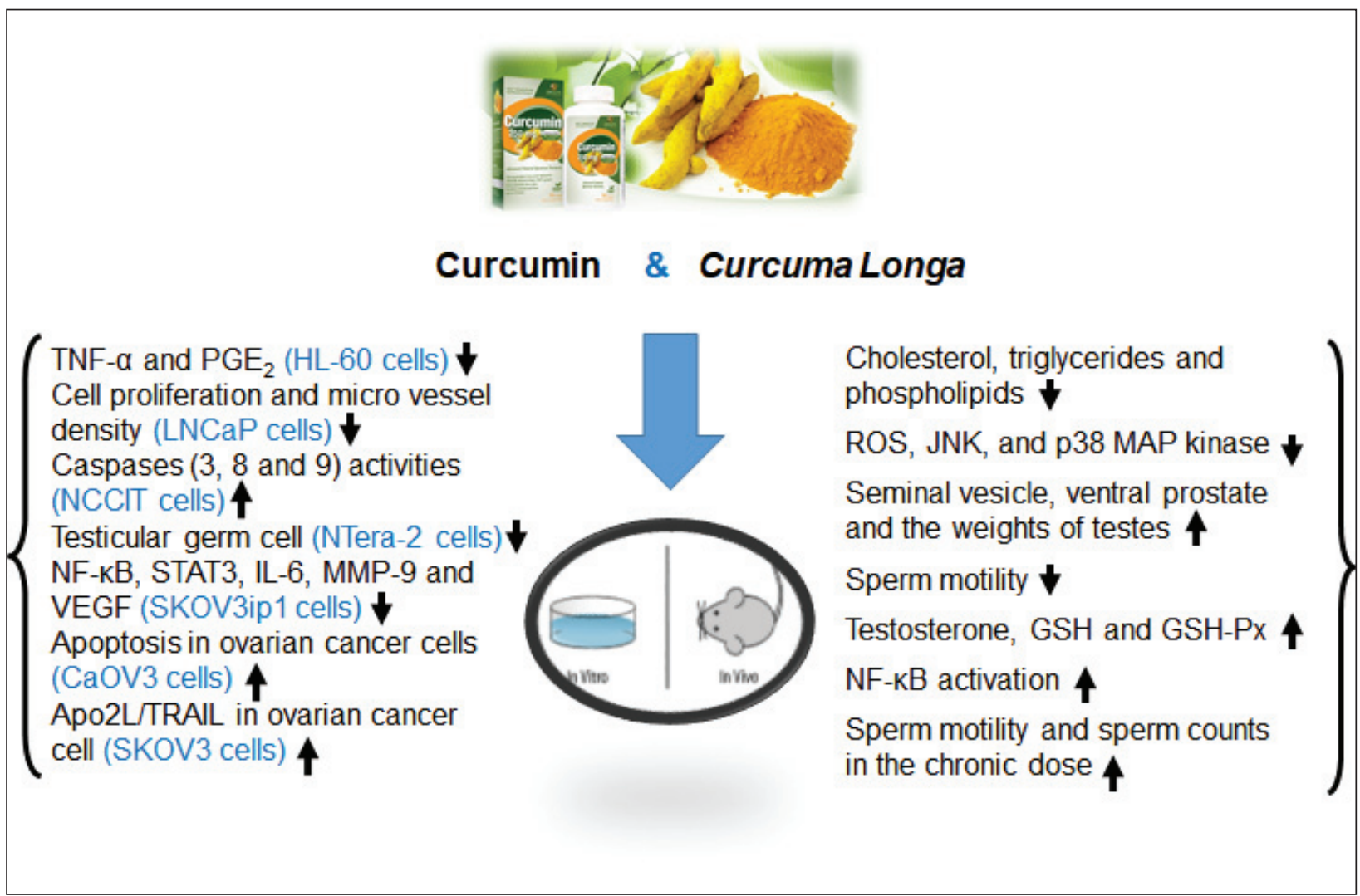

Figure 1. The effects of Curcuma longa and curcumin in some cell lines (left) and animal study (right). 
curcumin improved lindane-induced reproductive toxicity including decline in superoxide dismutase, catalase, and glutathione-s-transferase activity (Sharma and Singh 2010).

The effect of the curcumin against acute cadmium chloride $\left(\mathrm{CdCl}_{2}\right)$ toxicity on the reproductive system in male rats has been investigated (Oguzturk et al. 2012). $\mathrm{CdCl}_{2}$ led to a significant increase in oxidative stress. Curcumin $(1 \mathrm{mg} / \mathrm{kg})$ induced antioxidant effects and improved $\mathrm{CdCl}_{2}$-caused oxidative damage. The epididymal sperm concentration and sperm motility significantly decreased in $\mathrm{CdCl}_{2}$-exposed group and the sperm characteristics were recovered after treating with curcumin. In addition, $\mathrm{CdCl}_{2}$ administration resulted in vacuities, edema, hemorrhage, and acute inflammatory cells infiltration in the interstitial space. Administration of curcumin after $\mathrm{CdCl}_{2}$ toxicity reduced the severity of histopathological changes (Oguzturk et al. 2012).

The effects of the curcumin on inducible nitric oxide synthase (iNOS) expression, nuclear factor-kappa $\mathrm{B}$ (NF-kB) activation, and MAPK in the pathogenesis of testicular damage induced by cisplatin (CIS) have been investigated (Ilbey et al. 2009). Curcumin (200 mg/kg, p.o.) increased plasma testosterone levels, GSH levels, and glutathione peroxidase (GSH-Px) activity and decreased MDA and NO levels in the testicular tissue compared with the CIS-induced toxicity group (Ilbey et al. 2009).

The protective effects of the curcumin on chronic alcohol-exposed Leydig cells have been studied in male mice (Giannessi et al. 2008). The results have indicated that the rarefaction of cytoplasmic cells, increasing the diameter of mitochondria, reducing testosterone plasma level as well as necrosis of Leydig cells take place in the alcohol-fed mice. Administration of the curcumin $(80 \mathrm{mg} / \mathrm{kg})$ led to a reduction of the number of necrotic Leydig cells and the diameter of the mitochondria in alcohol plus curcumin-treated mice compared with alcohol-fed mice (Giannessi et al. 2008). These results have indicated that C. longa extracts and curcumin exhibit therapeutic effects on the male reproductive system via antioxidant and anti-inflammatory effects.

\section{The effect of $C$. longa and curcumin on the fe- male reproductive system}

In vitro (cellular) studies. Curcumin has been revealed to have antiviral, antibacterial anti-proliferation, and anti-angiogenic effects (Aggarwal et al. 2003). Curcumin has been also suggested to suppress the factors linked with tumorigenesis agents such as vascular endothelial growth factor (VEGF), phosphorylated signal transducers and activators of transcription 3 (STAT), and matrix metalloproteinase-9 (MMP-9) (Holt et al. 2005). Curcumin has been reported to have efficacy in ovarian carcinoma models through the anti-tumorigenic and anti-angiogenic mechanisms, and these effects are suggested to be mediated via the NF- $\kappa$ B, STAT3, interleukin-6 (IL6), MMP-9 and VEGF (Lin et al. 2007).

It has been documented that C. longa extract (0.4 $\mathrm{mg} / \mathrm{ml}$ ) may inhibit the cell growth in Chinese Hamster Ovary (CHO) cells. Furthermore, it has been reported that curcumin, in sub-lethal dose, increased Apo2L/TRAIL-caused cell death in CIS-resistant ovarian cancer cell lines (Wahl et al. 2007).

The curcumin has been suggested to suppress the proliferation and induce apoptosis in the human ovarian cancer cell line Ho-8910 (Shi et al. 2006). One of the most important tumor suppressors is p53, which can induce apoptosis by activating downstream genes in a sequence-specific manner (Harris and Levine 2005; Yu and Zhang 2005). It has been shown that treatment of the human ovarian cancer cell line Ho-8910 with curcumin for $24 \mathrm{~h}$ increased the total p53 level. This subject implies to a possible role of p53 in apoptosis caused by curcumin in Ho-8910 cells. In addition, it has been reported that treatment with curcumin decreased the level of antiapoptotic, such as Bcl-2 and Bcl- $\mathrm{X}_{\mathrm{L}}$, and increase the level of pro-apoptotic factor Bax in Ho-8910 cells (Shi et al. 2006).

The curcumin has also been suggested to arrest the cell-cycle in many different tumor cells through up-regulating Cdk-1, cdc2, NFkB (Park et al. 2002; Aggarwal et al. 2006). It has been reported that curcumin synergistically enhances the effect of platinum drugs such as cisplatin and oxaliplatin on the cell cycle arrest and ameliorates effect these drugs on ovarian cancer patients (Montopoli et al. 2009). AMP-activated protein kinase (AMPK) regulates the involved cellular processes in cellular energy status (Hardie and Carling 1997). Recently, scientific evidences have shown that AMPK activation may inhibit the cell proliferation and induce cell apoptosis in cancer cells (Nagata et al. 2004). It has been suggested that curcumin-induced cell death in CaOV3 ovarian cancer cells through activating p38-dependent AMPK is reversible by AMPK and p38 inhibitors (Pan et al. 2008).

The protective effect of $\mathrm{p} 53$, a tumor suppressor protein, against cancer has been well documented. p53 has been exhibited to involve in the cytotoxic action of chemotherapeutic drugs on cancer cells 
(Zunino et al. 1997; Siddik 2003). The curcumin has been shown to have cytotoxic effect on MCS consisting of three-dimensional aggregation of wild-type p53 OVCA429 or null p53 SKOV3 ovarian cancer cells (Watson et al. 2010).

In the curcumin-treated HEY ovarian carcinoma cells, the hallmarks of apoptosis such as nuclear condensation and nuclear and DNA fragmentation also happen (Martelli et al. 2001). The cleavage of PARP1 by caspase- 3 plays a crucial role in the initiation of the apoptosis (Cohen 1997). It has been reported that treatment with curcumin induces caspase-3 activation and the subsequent cleavage of PARP-1 in Hey cells and HO-8910 ovarian cancer cells (Shi et al. 2006). In addition, the scientific evidences have shown that curcumin-caused apoptosis in HEY ovarian carcinoma cells was associated with reduced expression of anti-apoptotic proteins including suvivin and Bcl-2 (Watson et al. 2010).

Recently, the curcumin has been shown to induce ceramide generation to stimulate cancer cell apoptosis (Moussavi et al. 2006). It seems that increasing agents of the intracellular ceramide levels could enhance tumor cell cytotoxicity and apoptosis caused by curcumin (Yu et al. 2012). Sphingosine kinase-1 (SphK1) has been proposed as a potent oncogene for ovarian cancer which is expressed in clinical ovarian tissues and in cultured ovarian cancer cells. It has been reported that SphK1 inhibition by siRNA knockdown and pharmacological inhibitor SKIII can facilitate curcumin-caused cytotoxicity and apoptosis (Yang et al. 2012).

The aquaporins (AQPs), integral membrane proteins, have been shown to be expressed in multiple epithelial and endothelial transporting fluids (Verkman 2005) as well as tumor cells (Moon et al. 2003; $\mathrm{Hu}$ and Verkman 2006). In in vitro and in vivo, AQPs can also facilitate tumor cell migration across the blood vessels (Hu and Verkman 2006). The curcumin has been documented to reduce epidermal growth factor (EGF)-caused AQP3 upregulation and cell migration in ovarian cancer cells (Ji et al. 2008).

In some studies, NF- $\kappa \mathrm{B}$ has been considered as an important player in tumor growth (Dobrovolskaia and Kozlov 2005; Van Laere et al. 2006), cell proliferation, apoptosis (Yamamoto and Gaynor 2001), and tumor chemo-resistance (Yu et al. 2005). Regarding to these effects, NF- $\kappa \mathrm{B}$ might be an important clinical therapeutic target. The results of many studies have indicated that curcumin inhibits NF- $\kappa \mathrm{B}$ activation, tumor growth, and angiogenesis in the ovarian carcinoma models when it was orally administered (Lin et al. 2007).
The curcumin have shown anti-apoptotic effects via inhibition of the angiogenesis such as inhibition of the fibroblast growth factor (FGF), VEGF, and angiopoietin 1 and 2 regulated cell adhesion molecules, such as endothelial leukocyte adhesion molecule-1 (ELAM-1), intracellular adhesion molecule-1 (ICAM1), and vascular cell adhesion molecule- 1 (VCAM-1) (Gururaj et al. 2002) and enhancement of the cancer inhibitor protein (p53) in normal cell lines and also activation of the pro-apoptotic agent, including angiogenesis and caspase 9, 8, and 3, in malignant cell lines (Cort et al. 2013).

In vivo (animal) studies. The antifertility effects of aqueous and ethanolic extract of rhizome of $C$. longa and seeds of Carum Carvi have been investigated (Thakur et al. 2009). The results have shown that both the aqueous and ethanolic extracts of rhizome of $C$. longa decreased the gonadotropin hormone (FSH and LH) levels and suppressed the estrus phase (Thakur et al. 2009).

It has also been reported that the curcumin can reduce the ovarian ischemia/reperfusion injury via decreasing the oxidative stress markers (Sak et al. 2013).

In another study, chlorpyrifos (CPF) (10 and 20 $\mathrm{mg} / \mathrm{kg}$ ) has been administered to mice by Gavage method, then histological alteration of the ovary and uterus was examined under the light microscope. In addition, oxidative stress levels were studied by determining the lipid peroxidation levels, and hormonal changes $(\mathrm{FSH})$ to evaluate the fertility rate. CPF-treated group has shown ruptured germinal epithelium with multiple nuclei and matured Graafian follicles with degenerated ovum. Corpus luteum cells were observed to be rudimentary. Unusual number of vacuolated spaces was observed in ovarian cortex. Thus, the study has revealed that CPF causes degeneration of Graafian follicle and germinal epithelium of ovary leading to infertility in female mice. Control uterus showed well-defined longitudinal and circular muscles on periphery with well-structured endometrial cells and glands. In CPF-treated group, the degeneration of circular and longitudinal muscles was observed on the periphery with clustered endothelial cells at lower concentration. At higher concentrations, degeneration in circular muscles was prominent. Longitudinal muscles were also on periphery with many vacuolated spaces along with vacuolated endometrial cells and glands which were also rudimentary in structure. The remediation effect with curcumin has been shown with better and more satisfactory results in histopathology as well as biochemical aspects (Raj et al. 2011). This study has 
shown that inhibition of implantation reduction of estrogen level and increment of progesterone level may be as the possible mechanism of antifertility effect of the ethanolic extract of C. longa.

\section{Conclusions}

In the recent years, the traditional medicine using natural products have received much more attention, because they were considered to be more safety for human than the synthetic drugs. C. longa and curcumin have been reported to possess anti-inflammatory, antioxidant, and anti-cancer effects. C. longa and curcumin protect gonad cells against ROS and carcinogenic agents. In addition, C. longa and curcumin may increase the anti-apoptotic factors such as $\mathrm{Bcl}-2$ and $\mathrm{Bcl}-\mathrm{X}_{\mathrm{L}}$ and decrease the apoptotic agents such as Bax in normal cell lines. Moreover, different effects of C. longa and curcumin are dependent on the doses and the type of cells used in various models studied. The therapeutic effect of the curcumin on the reproductive malignancy was more effective than C. longa extract in in vitro and in vivo studies. Generally, the curcumin showed anti-inflammatory and anti-apoptotic effects via inhibition of the angiogenesis, regulation of the cell adhesion molecules and enhancement of the cancer inhibitory protein (p53) in normal cell lines and also activation of pro-apoptotic agent induced angiogenesis and caspase 9, 8, and 3 in malignant cell lines.

\section{Acknowledgment}

We are thankful to the Research Council of Mashhad University of Medical Sciences for the partial support of this study.

\section{References}

Aggarwal BB, Kumar A, Bharti AC. Anticancer potential of curcumin: preclinical and clinical studies. Anticancer Res 23, 363-398, 2003.

Aggarwal S, Ichikawa H, Takada Y, Sandur SK, Shishodia S, Aggarwal BB. Curcumin (diferuloylmethane) downregulates expression of cell proliferation and antiapoptotic and metastatic gene products through suppression of IкBa kinase and Akt activation. Mol Pharmacol 69, 195-206, 2006.

Aggarwal BB, Harikumar KB. Potential therapeutic effects of curcumin, the anti-inflammatory agent, against neurodegenerative, cardiovascular, pulmonary, metabolic, autoimmune and neoplastic diseases. Int J Biochem Cell Biol 41, 40-59, 2009.

Akram M, Uddin S, Ahmed A, Usmanghani K, Hannan A, Mohiuddin E, Asif M. Curcuma longa and curcumin: a review article. Rom J Biol Plant Biol 55, 65-70, 2010.

Aktas C, Kanter M, Erboga M, Ozturk S. Anti-apoptotic effects of curcumin on cadmium-induced apoptosis in rat testes. Toxicol Indust Health 28, 122-130, 2012.

Ammon HP, Wahl MA. Pharmacology of Curcuma longa. Plant Med 57, 1-7, 1991.

Araujo CAC, Leon LL. Biological activities of Curcuma longa L. Memorias do Instituto Oswaldo Cruz 96, 723-728, 2001.

Ashok P, Meenakshi B. Contraceptive effect of Curcuma longa (L.) in male albino rat. Asia J Androl 6, 71-74, 2004.

Azza M, El-Wakf ME-S, Elhabiby MW, El-kholy E-GEA. Use of tumeric and curcumin to alleviate adverse reproductive outcomes of water: Nitrate pollution in male rats. Nat Sci 9, 229-239, 2011.

Chainani-Wu N. Safety and anti-inflammatory activity of curcumin: a component of tumeric (Curcuma longa). J Alter Compl Med 9, 161-168, 2003.

Cohen GM. Caspases: the executioners of apoptosis. Biochem J 326, 1-16, 1997.

Cort A, Timur M, Ozdemir E, Kucuksayan E, Ozben T. Synergistic anticancer activity of curcumin and bleomycin: an in vitro study using human malignant testicular germ cells. Mol Med Rep 5, 1481-1146, 2012.

Cort A, Timur M, Ozdemir E, Ozben T. Effects of curcumin on bleomycin-induced apoptosis in human malignant testicular germ cells. J Physiol Biochem 69, 289-296, 2013.

Cragg GM, Newman DJ. Plants as a source of anti-cancer agents. J Ethnopharmacol 100, 72-79, 2005.

Deshpande UR, Gadre SG, Raste AS, Pillai D, Bhide SV, Samuel AM. Protective effect of turmeric (Curcuma longa L.) extract on carbon tetrachloride-induced liver damage in rats. India J Exp Biol 36, 573-577, 1998.

Dobrovolskaia MA, Kozlov SV. Inflammation and cancer: when NF- $\kappa$ B amalgamates the perilous partnership. Curr Cancer Drug Targets 5, 325-344, 2005. 
Dorai T, Cao YC, Dorai B, Buttyan R, Katz AE. Therapeutic potential of curcumin in human prostate cancer. III. Curcumin inhibits proliferation, induces apoptosis, and inhibits angiogenesis of LNCaP prostate cancer cells in vivo. Prostate 47, 293-303, 2001.

Eigner D, Scholz D. Ferula asa-foetida and Curcuma longa in traditional medical treatment and diet in Nepal. J Ethnopharmacol 67, 1-6, 1999.

Farombi EO, Abarikwu SO, Adedara IA, Oyeyemi MO. Curcumin and kolaviron ameliorate di-n-butylphthalate-induced testicular damage in rats. Basic Clin Pharmacol Toxicol 100, 43-48, 2007.

Giannessi F, Giambelluca MA, Grasso L, Scavuzzo MC, Ruffoli R. Curcumin protects Leydig cells of mice from damage induced by chronic alcohol administration. Med Sci Monitor 14, BR237-BR242, 2008.

Gururaj A, Belakavadi M, Venkatesh DA, Marme D, Salimath BP. Molecular mechanisms of antiangiogenic effect of curcumin. Biochem Biophys Res Commun 297, 934-942, 2002.

Hardie DG, Carling D. The AMP-activated protein kinase. Eur J Biochem 246, 259-273, 1997.

Harris SL, Levine AJ. The p53 pathway: positive and negative feedback loops. Oncogene 24, 2899-2908, 2005.

Holt PR, Katz S, Kirshoff R. Curcumin therapy in inflammatory bowel disease: a pilot study. Dig Dis Sci 50, 21912193, 2005.

Hu M, Du Q, Vancurova I, Lin X, Miller EJ, Simms HH, Wang P. Proapoptotic effect of curcumin on human neutrophils: activation of the p38 mitogen-activated protein kinase pathway. Crit Care Med 33, 2571-2578, 2005.

$\mathrm{Hu}$ J, Verkman A. Increased migration and metastatic potential of tumor cells expressing aquaporin water channels. FASEB J 20, 1892-1894, 2006.

Ilbey YO, Ozbek E, Cekmen M, Simsek A, Otunctemur A, Somay A. Protective effect of curcumin in cisplatininduced oxidative injury in rat testis: mitogen-activated protein kinase and nuclear factor-kappa B signaling pathways. Hum Reprod 24, 1717-1725, 2009.

Ji C, Cao C, Lu S, Kivlin R, Amaral A, Kouttab N, Yang H, Chu W, Bi Z, Di W, Wan Y. Curcumin attenuates EGFinduced AQP3 up-regulation and cell migration in human ovarian cancer cells. Cancer Chemother Pharmacol 62, 857-865, 2008.

Jurenka JS. Anti-inflammatory properties of curcumin, a major constituent of Curcuma longa: a review of preclinical and clinical research. Altern Med Rev 14, 141-153, 2009.

Khazdair MR, Mohebbati R, Karimi S, Abbasnezhad A, Haghshenas M. The protective effects of Curcuma longa extract on oxidative stress markers in the liver induced by Adriamycin in rat. Physiol Pharmacol 20, 31-37, 2016.

Kowluru RA, Kanwar M. Effects of curcumin on retinal oxidative stress and inflammation in diabetes. Nutr Metab (Lond) 4, 8, 2007.

Kunchandy E, Rao MNA. Oxygen radical scavenging activity of curcumin. Int J Pharm 58, 237-240, 1990.

Kuttan R, Bhanumathy P, Nirmala K, George MC. Potential anticancer activity of turmeric (Curcuma longa). Cancer Lett 29, 197-202, 1985.

Lantz RC, Chen G, Solyom A, Jolad S, Timmermann B. The effect of turmeric extracts on inflammatory mediator production. Phytomedicine 12, 445-452, 2005.

Lin YG, Kunnumakkara AB, Nair A, Merritt WM, Han LY, Armaiz-Pena GN, Kamat AA, Spannuth WA, Gershenson DM, Lutgendorf SK, Aggarwal BB, Sood AK. Curcumin inhibits tumor growth and angiogenesis in ovarian carcinoma by targeting the nuclear factor- $\kappa$ B pathway. Clin Cancer Res 13, 3423-3430, 2007.

Martelli AM, Zweyer M, Ochs RL, Tazzari PL, Tabellini G, Narducci P, Bortul R. Nuclear apoptotic changes: an overview. J Cell Biochem 82, 634-646, 2001.

Mishra RK, Singh SK. Reversible antifertility effect of aqueous rhizome extract of Curcuma longa L. in male laboratory mice. Contraception 79, 479-487, 2009.

Mohanty I, Singh Arya D, Dinda A, Joshi S, Talwar KK, Gupta SK. Protective effects of Curcuma longa on ischemiareperfusion induced myocardial injuries and their mechanisms. Life Sci 75, 1701-1711, 2004.

Mohebbati R, Shafei MN, Soukhtanloo M, Mohammadian Roshan N, Khajavi Rad A, Anaeigoudari A, Hosseinian S, Karimi S, Beheshti F. Adriamycin-induced oxidative stress is prevented by mixed hydro-alcoholic extract of Nigella sativa and Curcuma longa in rat kidney. Avicenna J Phytomed 6, 86-94, 2016.

Montopoli M, Ragazzi E, Froldi G, Caparrotta L. Cell-cycle inhibition and apoptosis induced by curcumin and cisplatin or oxaliplatin in human ovarian carcinoma cells. Cell Prolif 42, 195-206, 2009.

Moon C, Soria J-C, Jang SJ, Lee J, Obaidul Hoque M, Sibony M, Trink B, Chang YS, Sidransky D, Mao L. Involvement of aquaporins in colorectal carcinogenesis. Oncogene 22, 6699-6703, 2003.

Moussavi M, Assi K, Gomez-Munoz A, Salh B. Curcumin mediates ceramide generation via the de novo pathway in colon cancer cells. Carcinogenesis 27, 1636-1644, 2006. 
Nagata D, Takeda R, Sata M, Satonaka H, Suzuki E, Nagano T, Hirata Y. AMP-activated protein kinase inhibits angiotensin II-stimulated vascular smooth muscle cell proliferation. Circulation 110, 444-451, 2004.

Naik RS, Mujumdar AM, Ghaskadbi S. Protection of liver cells from ethanol cytotoxicity by curcumin in liver slice culture in vitro. J Ethnopharmacol 95, 31-37, 2004.

Oguzturk H, Ciftci O, Aydin M, Timurkaan N, Beytur A, Yilmaz F. Ameliorative effects of curcumin against acute cadmium toxicity on male reproductive system in rats. Andrologia 44, 243-249, 2012.

Pan W, Yang H, Cao C, Song X, Wallin B, Kivlin R, Lu S, Hu G, Di W, Wan Y. AMPK mediates curcumin-induced cell death in CaOV3 ovarian cancer cells. Oncol Rep 20, 1553-1559, 2008.

Park MJ, Kim EH, Park IC, Lee HC, Woo SH, Lee JY, Hong YJ, Rhee CH, Choi SH, Shim BS, Lee SH, Hong SI. Curcumin inhibits cell cycle progression of immortalized human umbilical vein endothelial (ECV304) cells by up-regulating cyclin-dependent kinase inhibitor, p21WAF1/CIP1, p27KIP1 and p53. Int J Oncol 21, 379-384, 2002.

Purohit A. Antifertility efficacy of Curcuma longa (50\% E to H extract) with special referance to serum biochemistry and fertility test. Anc Sci Life 18, 192-194, 1999.

Qureshi S, Shah A, Ageel A. Toxicity studies on Alpinia galanga and Curcuma longa. Planta Med 58, 124-127, 1992.

Raj A, Singh A, Sharma A, Singh N, Kumar P, Bhatia V. Antifertility activity of medicinal plants on reproductive system of female rat. Int J Bio-Eng Sci Technol 2, 44-50, 2011.

Sahoo DK, Roy A, Chainy GB. Protective effects of vitamin E and curcumin on L-thyroxine-induced rat testicular oxidative stress. Chem Biol Interac 176, 121-128, 2008.

Sak ME, Soydinc HE, Sak S, Evsen MS, Alabalik U, Akdemir F, Gul T. The protective effect of curcumin on ischemiareperfusion injury in rat ovary. Int J Surg 11, 967-970, 2013.

Sharma RA, Gescher AJ, Steward WP. Curcumin: the story so far. Eur J Cancer 41, 1955-1968, 2005.

Sharma P, Singh R. Protective role of curcumin on lindane induced reproductive toxicity in male Wistar rats. Bull Environ Contam Toxicol 84, 378-384, 2010.

Shi M, Cai Q, Yao L, Mao Y, Ming Y, Ouyang G. Antiproliferation and apoptosis induced by curcumin in human ovarian cancer cells. Cell Biol Int 30, 221-226, 2006.

Shukla PK, Khanna VK, Khan MY, Srimal RC. Protective effect of curcumin against lead neurotoxicity in rat. Hum Exp Toxicol 22, 653-658, 2003.

Siddik ZH. Cisplatin: mode of cytotoxic action and molecular basis of resistance. Oncogene 22, 7265-7279, 2003.

Srivastava G, Mehta JL. Currying the heart: curcumin and cardioprotection. J J Cardiovasc Pharmacol Ther 14, 22-27, 2009.

Swamy MV, Citineni B, Patlolla JMR, Mohammed A, Zhang Y, Rao CV. Prevention and treatment of pancreatic cancer by curcumin in combination with omega-3 fatty acids. Nutr Cancer 60, 81-89, 2008.

Thakur S, Bawara B, Dubey A, Nandini D, Chauhan NS, Saraf DK. Effect of Carum carvi and Curcuma longa on hormonal and reproductive parameter of female rats. Int J Phytomed 1, 31-38, 2009.

Van Laere SJ, Van der Auwera I, Van den Eynden GG, Elst HJ, Weyler J, Harris AL, van Dam P, Van Marck EA, Vermeulen PB, Dirix LY. Nuclear factor-KB signature of inflammatory breast cancer by cDNA microarray validated by quantitative real-time reverse transcription-PCR, immunohistochemistry, and nuclear factorKB DNA-binding. Clin Cancer Res 12, 3249-3256, 2006.

Verkman A. More than just water channels: unexpected cellular roles of aquaporins. J Cell Sci 118, 3225-3232, 2005.

Wahl H, Tan L, Griffith K, Choi M, Liu JR. Curcumin enhances Apo2L/TRAIL-induced apoptosis in chemoresistant ovarian cancer cells. Gynecol Oncol 105, 104-112, 2007.

Watson JL, Greenshields A, Hill R, Hilchie A, Lee PW, Giacomantonio CA, Hoskin DW. Curcumin-induced apoptosis in ovarian carcinoma cells is p53-independent and involves p38 mitogen-activated protein kinase activation and downregulation of Bcl-2 and survivin expression and Akt signaling. Mol Carcinog 49, 13-24, 2010.

Wilken R, Veena MS, Wang MB, Srivatsan ES. Curcumin: A review of anti-cancer properties and therapeutic activity in head and neck squamous cell carcinoma. Mol Cancer 10, 12, 2011.

Yamamoto Y, Gaynor RB. Therapeutic potential of inhibition of the NF- $\mathrm{kB}$ pathway in the treatment of inflammation and cancer. J Clin Invest 107, 135-142, 2001.

Yang Yl, Ji C, Cheng L, He L, Lu CC, Wang R, Bi ZG. Sphingosine kinase-1 inhibition sensitizes curcumin-induced growth inhibition and apoptosis in ovarian cancer cells. Cancer Sci 103, 1538-1545, 2012.

Yu J, Zhang L. The transcriptional targets of p53 in apoptosis control. Biochem Biophys Res Commun 331, 851-858, 2005.

Yu YY, Li Q, Zhu ZG. NF-kappaB as a molecular target in adjuvant therapy of gastrointestinal carcinomas. Eur J Surg Oncol 31, 386-392, 2005. 
Yu T, Li J, Qiu Y, Sun H. 1-Phenyl-2-decanoylamino-3-morpholino-1-propanol (PDMP) facilitates curcumin-induced melanoma cell apoptosis by enhancing ceramide accumulation, JNK activation, and inhibiting PI3K/AKT activation. Mol Cell Biochem 361, 47-54, 2012.

Zhou C, Zhao XM, Li XF, Wang C, Zhang XT, Liu XZ, Ding XF, Xiang SL, Zhang J. Curcumin inhibits AP-2 $\gamma$ induced apoptosis in the human malignant testicular germ cells in vitro. Acta Pharmacol Sin 34, 1192-1200, 2013.

Zunino F, Perego P, Pilotti S, Pratesi G, Supino R, Arcamone F. Role of apoptotic response in cellular resistance to cytotoxic agents. Pharmacol Ther 76, 177-185, 1997. 